University of Wollongong

Research Online

Faculty of Engineering and Information

Faculty of Engineering and Information

Sciences - Papers: Part A

Sciences

$1-1-2017$

Formative assessment to develop oral communication competency using YouTube: self- and peer assessment in engineering

Sasha Nikolic

University of Wollongong, sasha@uow.edu.au

David Stirling

University of Wollongong, stirling@uow.edu.au

Montserrat Ros

University of Wollongong, montse@uow.edu.au

Follow this and additional works at: https://ro.uow.edu.au/eispapers

Part of the Engineering Commons, and the Science and Technology Studies Commons

Research Online is the open access institutional repository for the University of Wollongong. For further information contact the UOW Library: research-pubs@uow.edu.au 


\title{
Formative assessment to develop oral communication competency using YouTube: self- and peer assessment in engineering
}

\begin{abstract}
Obtaining oral communication competency is an important skill for engineering students to prepare them for interacting and working in any professional setting. For engineers, it is also important to be able to present technical information to non-technical audiences. To ensure oral competency, a non-graded formative assessment approach using video with self- and peer assessment was introduced into a finalyear engineering thesis course. A low workload approach was used due to growing student numbers and higher pressures on academic staff. A quasi-experimental design was used to investigate the differences between traditional delivery, self-assessment and combined self-assessment with peer feedback. The study found that the formative models were seen by students to help develop their presentation skills. However, the results showed no significant improvement compared to the traditional method. This could be due to previous presentation practice within the degree or more probable, the lack of incentive for weaker students to engage and improve due to the ungraded nature of the activity.
\end{abstract}

\section{Keywords}

competency, communication, engineering, oral, peer, develop, assessment, formative, self-, youtube:

\section{Disciplines}

Engineering | Science and Technology Studies

\section{Publication Details}

S. Nikolic, D. Stirling \& M. Ros, "Formative assessment to develop oral communication competency using YouTube: self- and peer assessment in engineering," European Journal of Engineering Education, vol. 43, (4) pp. 538-551, 2018. 


\title{
Formative Assessment to Develop Oral Communication Competency Using YouTube: Self- and Peer Assessment in Engineering
}

\begin{abstract}
Obtaining oral communication competency is an important skill for engineering students to prepare them for interacting and working in any professional setting. For engineers, it is also important to be able to present technical information to non-technical audiences. To ensure oral competency, a non-graded formative assessment approach using video with self and peer assessment was introduced into a final year engineering thesis course. A low workload approach was used due to growing student numbers and higher pressures on academic staff. A quasiexperimental design was used to investigate the differences between traditional delivery, self-assessment, and combined self-assessment with peer feedback. The study found that the formative models were seen by students to help develop their presentation skills. However, the results showed no significant improvement compared to the traditional method. This could be due to previous presentation practice within the degree or more probable, the lack of incentive for weaker students to engage and improve due to the ungraded nature of the activity.
\end{abstract}

Keywords: communication; formative assessment; oral presentations; peer assessment; self-assessment; SPARK ${ }^{\text {PLUS }}$; video; YouTube

\section{Introduction}

Communication skills are considered an integral part of an engineering curriculum. This is evidenced by the need for students to demonstrate effective communication skills as a part of the Washington Accord accreditation standards for Engineers (Cochrane and O'Donoghue 2008; Morales and Rosa 2008; Prescott et al. 2012; Kunioshi et al. 2012; Berjano, Sales-Nebot, and Lozano-Nieto 2013). Oral communication is an important competency to be achieved for all disciplines as it enables students to function successfully in a professional environment, a skill that must be transferred from the classroom to the workplace (Živković 2014). Trevelyan (2014) outlines this importance by highlighting that technical collaboration occupies at least $60 \%$ of the work of engineers. However, recent research has highlighted weaknesses in current engineering 
education of adequately preparing students for professional practice in the workplace (Male and King 2014; Nabila et al. 2014; Edwards et al. 2015). In terms of oral communication skills, this could be due to claims that little pedagogical design is used to develop communication competence (Bower et al. 2011; Brown* and Morrissey 2004). Consequently for the engineering community it is about finding a balance between improving oral competency and enhancing exposure to technical engineering material (Cochrane 2009).

In order for universities to improve student communication skills, it is important to reflect on current practice. Within the School of Electrical, Computer and Telecommunications Engineering at the University of Wollongong, the historical approach to developing oral communication skills has been through a process of student presentation, followed by verbal feedback and an assessment mark. In this scenario the process of learning is based on the experience of presenting and reflecting on the comments of the assessors and their marks. The downfall of this approach is that any large increase in student numbers places a logistical strain to provide sufficient feedback to aid learning (Cochrane and O'Donoghue 2008; Tazijan et al. 2012). This subsequently leads to an investigation into new methods to improve engineering oral communication skills that would take advantage of the learning potential of assessment (Taras 2008). Through formative assessment, the assessment 'is specifically intended to provide feedback on performance to improve and accelerate learning' pg.64 (Nicol and Milligan 2006). However, while formative assessment has been shown to be beneficial to learning, it can add significant workload for the teaching staff (Poza-Lujan et al. 2016). Therefore, it is important to understand how formative assessment can be applied in the most productive format possible - that is, in terms of both learning and workload. 
The use of video feedback has been used across many disciplines over a long period of time as an effective method to improve learning and provide effective feedback. Examples include: teacher development and training (Abbott, Wulff, and Szego 1989; Nikolic et al. 2015), enhancing the learning of concepts (Lee and Lehto 2013; Vial et al. 2015; Nikolic 2015), developing authentic learning experiences (Kearney and Schuck 2006; Rodriguez, Ajjan, and Honeycutt 2014), and most important to this study improving learning via feedback (Barry 2012; Maloney et al. 2013; Hsia, Huang, and Hwang 2016). The advantages of the video medium, is that it is a multi-sensory environment and that students are exposed to it in their daily lives (McNulty and Lazarevic 2012). A disadvantage of video feedback is that it can provide too much sensory information, causing confusion for some students (Schmidt and Wrisberg 2008).

The amount of feedback provided to students can be better directed by incorporating peer assessments. Studies by Kim (2014) and Liow (2008) have already begun to explore how peer assessment can be used to improve the oral competency of final year engineering students. The advantage of peer assessments is that they foster student learning, providing many opinions and viewpoints for students to reflect upon (Chen 2010). Additionally, peer assessment requires students to pay particular attention to performance criteria making them more aware of the requirements for their own presentation and develop appraisal skills (Topping 1998; Cheng and Warren 2005). The educational benefits of peer assessment can be further supported by providing a mechanism that if designed correctly can also reduce the workload of teaching staff (Topping 2003). A number of recent research studies (De Grez, Valcke, and Roozen 2012; Tazijan et al. 2012; De Grez and Valcke 2013; Rodriguez, Ajjan, and Honeycutt 2014; Hsia, Huang, and Hwang 2016) have attempted to understand the benefits and 
relationships between self and peer assessment, ability to assess, and to determine the most effective design. However, more data from across disciplines, countries and educational levels is needed.

\section{Purpose of Study}

The purpose of this study is to determine if a low teacher workload, formative assessment approach could be used to improve oral communication competency of fourth year engineering undergraduate students undertaking thesis. A thesis is a major research project that provides evidence that a student can apply knowledge developed throughout the degree to solve a problem in their field. A quasi-experimental design (using existing groups) was used to measure the impact video, together with self and peer assessment had on the performance of a live presentation. Factors of interest include improvement of learning, the student experience and staff workload. The findings from this study will help educators seeking to implement an efficient and effective formative assessment to improve oral communication skills. In the next section of the paper a review of related work is outlined, followed by research design, results and discussion.

\section{Related Work}

A review of oral presentation competency in higher education was conducted by van Ginkel et al. (2015b), reviewing 52 publications across 20 years. The review found that across many disciplines such as financial, business and technical professions more work is required to build student's oral competency, with little space in the curriculum to do so. The authors argue that in order to develop oral competency a systematic approach is needed, leading to the development of seven design principles: learning objectives, learning task, behaviour modelling, opportunity to practice, intensity and timing of 
feedback, peer-assessment and self-assessment. The assessment principles strongly recommend the use of video to improve self-efficacy, competency and attitude.

In an effort to improve learning efficiency with large classes Cochrane and O'Donoghue (2008) developed a software program Virtual-i Presenter (ViP) and investigated its effectiveness. The software combined PowerPoint slides with video from a webcam to allow students to practice the delivery of their presentations. The students were able to practice as many times as they wished by recording and watching their performance. When they were satisfied they submitted the recorded video via the ViP application to their peers and teaching staff for assessment and feedback. Excerpts of the videos were also shared in class to provide additional feedback. Using a sample of 19 students, the students practiced their presentation on average four times. Student responses suggested that the process supported their ability to improve PowerPoint presentations, and that this was a good way to undertake presentations. This process was repeated in a civil engineering setting (Cochrane 2009) where English was a second language for the students (Tazijan et al. 2012). These studies confirmed that students believed that the process helped them give a better delivery and also improve their confidence. They also appreciated the ability to see themselves, and this also facilitated a better understanding of nonverbal communication skills.

A similar study by Barry (2012) recorded live group presentations of 46 business students. Students watched each recorded presentation within the group and undertook self and peer assessment. Comparable results were obtained with students approving of the process that enabled them to view their own performance in comparison to others. With students obtaining multiple sources of feedback there was also no need to seek out and debate various marks given by a single assessor. Interesting, the students also generally scored their own performance lower than that of 
peers and the teacher. A slight variant to this approach, but with similar positive findings by McNulty and Lazarevic (2012) and Maloney et al. (2013) used video recordings in a role play format. The outcomes of the studies could have been improved if the study compared if the video was able to improve live presentation skills. A small scale study of 16 graduate students studying teaching by Guo (2013) did make this comparison. The author found that the participants in the experimental group that watched the video and participated in reflection exercises outperformed the students in the control group.

A key component of the video based approach is the assumption that students are competent in undertaking self and peer assessment. This assumes that students can reflect on their own performance and successfully follow a marking rubric. Koole et al. (2012) identified three elements of reflection ' 1 . Awareness of self and the situation; 2. Critical analysis and understanding of both self and the situation; 3. Development of new perspectives to inform future actions' (pg. 1).

In an attempt to understand if students were able to respond to both selfassessment and feedback Rodriguez, Ajjan, and Honeycutt (2014) conducted a two part role play simulation on 91 marketing students. A role-play was recorded and evaluated by peers and instructor, followed by self-assessment and review of feedback by the students. A second role-play was conducted and the results were compared. The study found a substantial improvement in the second role-play in student verbal and nonverbal communication skills. However, a control group was not used in this study to determine the impact of simply doing a second performance or the difference between the selfassessment and the feedback provided.

A second approach to determine students competency in self and peer assessment was undertaken by De Grez, Valcke, and Roozen (2012) on 57 business 
administration students. The study was used to compare the student's ability in assessing compared to that of teaching staff. Student presentations were recorded and then marked via self-assessment, marked by peers, and marked by a number of teachers. In terms of self-assessment the study found that teachers provided lower scores than the students self-rating. The analysis of peer assessment against teacher assessment produced the same outcome, suggesting that teachers and students interpret the marking rubric differently. Interestingly, it was also found that in terms of peer assessments male students rated female presenters more favourably.

A recent study by Hsia, Huang, and Hwang (2016) tried to determine if there was any difference when using three different forms of online peer assessment with video. The study examined simply using peer comments, using only peer ratings, and using a combination of ratings and comments for improving dance performance. The study involving 102 students found that peer comments alone were correlated with the least improvement in performance, while the mixed feedback provided for the greatest improvement. The authors believed that this was because students paid greater attention to the performance being marked. The students that provided both comments and ratings also had a high correlation when comparing the marks to the teachers.

The studies highlighted have shown that self and peer assessment can be beneficial to learning. In order to determine if there was a learning impact in who provided the feedback on oral presentation competence van Ginkel et al. (2015a) studied 144 undergraduate life sciences students. The study compared the impact of teacher feedback, peer feedback, self-assessment and peer feedback guided by a tutor. Feedback from all four sources was found to significantly increase student cognition towards presenting. However, the impact on student presentation behaviour was most significant for the teacher. 
Using the traditional method of the teacher providing oral feedback after a live presentation, Elfering, Grebner, and Wehr (2012) investigated the amount of feedback retained by the student. They implemented the study on 101 psychology Master thesis students. In the study they found that on average $40 \%$ of the feedback was missed by the students. The more in-depth the feedback the lower the retention, suggesting that brief, to the point information is required. They suggested that written feedback could negate the retention loss.

It is of great interest to understand how many presentations are required for optimum learning of presentation skills. A study on role playing sales presentations by Calcich and Weilbaker (1992) found that a significant improvement occurred with the second presentation, with no statistically significant improvement after. If students have had multiple experiences in providing presentations this may affect the amount of improvement possible in future activities.

\section{Research Method}

\subsection{Background}

The study was conducted in the first component of a fourth year engineering thesis course consisting of electrical, computer, mechatronic and telecommunications engineering students. The first component involves students starting with a six credit point course focusing on project specification, literature review and research design. As a result, student workload is high, with only one week provided for students to prepare the oral presentation after the final submission of a written report. Being a technical subject the delivery of technical content plays a major role in the oral presentation. The majority of students are male and approximately half of the students are international. 
Students are required to undertake a number of live oral presentations each year starting from first year, with most being group-based presentations. The thesis presentation is the first major presentation to be delivered individually with a large technical component. Consequently a limitation of this study may be that students have already gained substantial practice, even if it is group based.

\subsection{Research Design}

A quasi-experimental research design was chosen to investigate the impact that video, together with self and peer feedback had on presentation skills. The students were not placed into groups randomly, with groups consisting of all students enrolled in the course in a particular semester, explaining the need for a quasi-experimental design. The study was conducted over five teaching semesters across two and a half years commencing in July 2013. In all five teaching semesters the students were presented with a lecture on undertaking presentations by a professional consultant. The same consultant and lecture was used across all five teaching semesters. The students were also provided with exemplar presentations to watch on YouTube. The exemplar presentations were recordings of previous student presentations that had been awarded the highest presentation marks in the course.

In each teaching semester one of three scenarios were tested. The use of groups within a semester (and reason for quasi-experimental design) was not used to remove the possibility of a grade disadvantage between students. The outline of the three groups is defined in Table 1. The first two teaching semesters were treated as the control group, Group One. Group One required the students to undertake the standard graded live presentation used for more than ten years. Students enrolled in the following two teaching semesters formed Experimental Group Two. Group Two required the students to undertake a video presentation including self-reflection, grade their own performance 
and provide feedback and grades to a group of peers, receive feedback from their peers and then conduct the graded live presentation. The various stages are outlined in Table 2. Students enrolled in the final semester formed Experimental Group Three. Group Three followed a similar process to Group Two except for the exclusion of receiving feedback from peers. In this scenario, self-reflection was based solely on evaluating their own performance and comparing this to the performance of others in the group. The students were not made aware that they would not be receiving the feedback until after the peer assessment stage had been completed. This component of the study was only conducted over one semester as the authors wanted to analyse the data and ensure that student learning was not compromised by not receiving peer feedback.

TABLE 1: Overview of design parameters of the three control groups

\begin{tabular}{|c|c|c|c|c|c|c|c|}
\hline Exp. & Semester $/$ & Average & No. & Australian & International & Male & Female \\
& Year & 'Weighted & Students & Students & Students & Students & Students \\
& & Average & & & & & \\
\hline One & Sem2 2013 & 66 & 21 & 13 & 8 & 16 & 5 \\
\hline One & Sem1 2014 & 69 & 51 & 23 & 28 & 44 & 7 \\
\hline Two & Sem2 2014 & 69 & 24 & 14 & 10 & 18 & 6 \\
\hline Two & Sem1 2015 & 67 & 60 & 29 & 31 & 51 & 9 \\
\hline Three & Sem2 2015 & 67 & 17 & 10 & 7 & 16 & 1 \\
\hline
\end{tabular}


TABLE 2: A summary of the four processes used in the study

\begin{tabular}{|c|c|}
\hline Process & Requirements \\
\hline YouTube & $\begin{array}{l}\text { Student would record video of presentation and review. Student } \\
\text { can repeat process until satisfied or until due date of assessment. } \\
\text { Video is uploaded to YouTube. Video can be uploaded as private } \\
\text { if student had privacy concerns. }\end{array}$ \\
\hline Self and peer Assessment & $\begin{array}{l}\text { Coordinator allocates students into groups of six to eight. The } \\
\text { student must grade their own performance and the performance } \\
\text { of the peers in their group. They must also provide written } \\
\text { feedback on the performance. Examples of feedback are } \\
\text { provided in the lecture. The grades are not used as formal } \\
\text { assessment. }\end{array}$ \\
\hline $\begin{array}{l}\text { Peer Assessment Feedback } \\
\text { Received }\end{array}$ & $\begin{array}{l}\text { Student receives a summary of grades provided by peers } \\
\text { together with feedback. In addition, feedback is provided as to } \\
\text { whether the student over or under estimated their own } \\
\text { performance }\end{array}$ \\
\hline Presentation & $\begin{array}{l}\text { Student undertakes presentation in front of a live audience of } \\
\text { approximately two members of staff and thirty students. Marks } \\
\text { from staff are used towards final grade }\end{array}$ \\
\hline
\end{tabular}

A representation of the differences across the three experimental groups is shown in Table 3. The three groups all had a similar weighted average mark, which was used to compare student capability between groups. In all groups the only assessable component contributing to final grades was a live presentation. This was because adding a teacher graded component would add to staff workload, being against the goals of this study. Peer assessment marks could have been used but decided against due to concerns 
about reliability. A concurrent study in a different course is being used to investigate this reliability. Therefore, to encourage participation in all activities a small set of penalty marks were used.

TABLE 3: Structure of the three experimental designs

\begin{tabular}{|c|c|c|c|c|}
\hline Exp. & Activity & Activity & Activity & Activity \\
\hline One & & & & \\
\hline Two & YouTube & Self \& Peer & Peer Assessment & Presentation \\
\hline Three & YouTube & Self \& Peer & & Feedback Received \\
& & Assessment & & \\
\hline
\end{tabular}

At the end of each semester students were invited to complete a survey on their experience in the subject. This included questions that were designed to evaluate student perceptions of the experience.

\subsection{Presentation}

The common activity across all three experimental groups was the live presentation activity. The live presentation has historically played an important role within the thesis course. The presentation is conducted at the end of the teaching semester and is focused on presenting the students research to a general audience. A student presentation must not exceed twelve minutes and is conducting in front of an audience of approximately two staff members and thirty students. The staff members in attendance undertake the grading of the performance.

The marking rubric used is based on three areas of competence. The first being 'presentation style \& oral delivery' (25\%). Followed by 'technical content' (50\%), and 
the last being 'resources, diagrams and other aids' (25\%). The technical content component has the highest weighting and is based on competencies required by Engineers Australia such as 'an ability to communicate with the engineering team and the community at large' (Engineers Australia 2008) and from the Australian Qualifications Framework 'transmit knowledge, skills and ideas to others' (Australian Government 2016). The students must present the technical content in a manner comprehensible by a non-engineer. A limitation of this study could be that the rubric is well suited to the presentation of a thesis, but does not concentrate simply on oral delivery as found in many other oral communication studies.

\subsection{YouTube}

For Groups Two and Three the students were required to record a practice presentation, an ungraded activity. However, students would receive penalty marks for nonparticipation. Students could undertake the recording at any location including a spare lecture theatre or tutorial room or at home. The only condition was that the student and presentation slides must be seen at all times. Students could undertake this at home by connecting their smart phone or laptop to their television, or simply use their computer monitor to display the presentation. The students were instructed to watch the video and reflect on their performance. No editing of the video was permitted, however, the process of recording and reflection could be repeated as many times as needed. Lighting, camera angles and image quality were ignored. A smart phone was recommended for recording the video and this may have required the assistance of a friend. When a student was eventually satisfied with their practice presentation they were required to upload the video to YouTube and provide the lecturer with the web address. If privacy was a concern, the recording could be set to private on YouTube. Through the use of a popular site such as YouTube, students are familiar and 
comfortable with the technology and this removes the technical logistics from the teaching staff that would add significant workload (Maloney et al. 2013; Rodriguez, Ajjan, and Honeycutt 2014). The only work for the teaching staff at this stage is to allow students to upload their presentation link onto the learning management system.

\subsection{Self and Peer Assessment}

With the videos uploaded the subject coordinator allocated the students into groups of six to eight for groups two and three. Groups of this size were selected due to research by Hafner and Hafner (2003) and Dannefer et al. (2005) that at least five to six peers are needed for reliable feedback. Students are provided with the YouTube link to the videos. If a video is made private the student must provide access to their group members.

In the lecture, prior to the activity the students are introduced to an online tool known as "SPARK+". This online tool is primarily used for the confidential self and peer assessment of students that are involved in teamwork. Studies have shown that SPARK + can be used to develop professional skills, provision feedback in large classes and improve the dynamics of teamwork (Freeman and McKenzie 2002; Willey and Gardner 2008).

The students were shown how to use the online tool and provided with examples of the type of grades and feedback required. It is important to note that the grades given or the feedback provided is not marked. However, a penalty mark is applied for nonparticipation. Being a thesis subject, higher order skills of analysis, synthesis and evaluation are discussed and mapped to the assessment tasks for the students (Anderson et al. 2001). This provides context for the assessment tasks the students will be required to undertake. 
As the purpose of the self and peer assessment is to improve learning, and the marks did not contribute towards the final grade, the standard marking scale was not applied. According to literature, students and teachers interpret criteria of a marking rubric differently, with a slight positive bias (Freeman 1995; De Grez, Valcke, and Roozen 2012; De Grez and Valcke 2013). Therefore, a different approach was taken, considering the application of SPARK + and the learning objective of the task. Using observational learning (Bandura 1997) the rubric was designed to emphasize the comparison of performance to aid learning. To accomplish this a rating scale of Well Below Average, Below Average, Average, Above Average and Well Above Average was used. SPARK+ uses a sliding scale on a bar for grading purposes. The expectation was that this scale would be easy for students to relate to and enforce a comparison between presentations. In doing so they will become self-aware of positive and negative traits in conducting an oral presentation.

Using the SPARK+ software students firstly must rate their own performance against the oral communication competencies used in the live presentation. Secondly, they watch the YouTube videos of each of the group members and complete the marking rubric. In addition, the students also provided written constructive feedback (both positive and negative). As was evidenced by Hsia, Huang, and Hwang (2016) the mixed assessment approach was the most effective to improve learning.

\subsection{Peer Assessment Feedback Received}

In Group Two students received confidential feedback from their peers via SPARK+. The comparison between groups two and three is to determine if any improvement to oral presentations is gained from the peer feedback compared to only undertaking observational learning. 
Students receive an average score from the group members for each of the criteria in the marking rubric as well as a collective list of written feedback. The students also receive a SAPA (Self-Assessment to Peer-Assessment) factor. This factor is calculated by SPARK + and indicates if the student under or over estimates their ability. This provides the students a great opportunity to develop their critical reflection and evaluation skills (Beamish et al. 2009) and improve their presentation skills.

\section{Results and Discussion}

\subsection{Live Oral Presentation}

The presentation marks for the three groups was entered into JMP ${ }^{\circledR}$ Pro 11 (Statistical Discovery software from the SAS Institute). A summary of the findings is shown in Table 4 examining the difference in average student mark, differences between Australian and international students, and differences between male and female students. Figure 1 provides a visual representation of the distribution of marks across the three groups. The standard deviation in marks is $7.7,9.7$ and 10.7 across groups 1,2 and 3 respectively.

TABLE 4: Summary of findings

\begin{tabular}{|l|c|c|c|c|c|c|c|c|c|c|}
\hline Exp. & Mean & Sig. & Mean & Sign. & Mean & Sig. & Mean & Sig. & Mean & Sig. \\
& All & Diff. & Aus. & Diff. & International & Diff. & Male & Diff. & Female & Diff. \\
& Students & & Students & & Students & & Students & & Students \\
\hline One & 77.4 & No & 79.4 & No & 75.4 & No & 77.7 & No & 75.9 & No \\
\hline Two & 76.8 & No & 78.3 & No & 75.3 & No & 76.9 & No & 76.8 & No \\
\hline Three & 74.0 & No & 77.1 & No & 69.5 & No & 74.0 & No & 75.0 & No \\
\hline
\end{tabular}




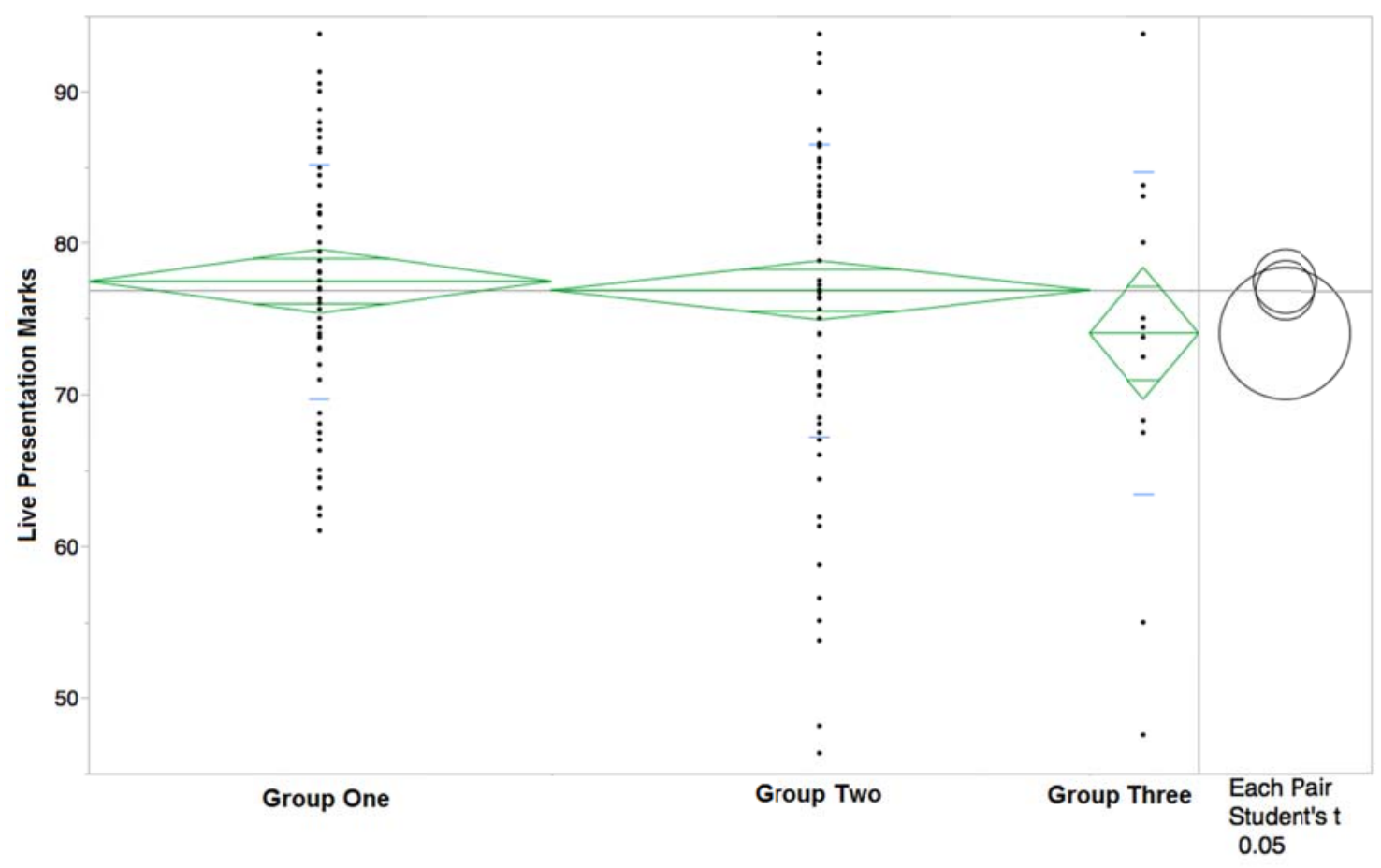

FIGURE 1: The distribution of marks for all students across the three groups

The summarized data in Table 4 indicates that there was no significant difference between the control and experimental groups. In terms of improving oral competency during a live performance the formative assessment was shown to have made little difference. As was suggested by Calcich and Weilbaker (1992) that statistically significant increases in oral competency stop after the second presentation, the number of oral presentations completed by the students in the first three years of the degree could have contributed to this absence of significant improvement. This is because students gain substantial tacit presentation knowledge through experience (Price and O'Donovan 2006). That is, an improvement may have occurred but not enough to be justified as a significant improvement.

A second reason could be associated with the allocation of marks by the assessors. As was seen in Figure 1, the marks across the three groups are concentrated in a range between 65 and 85 . This could have been seen as a default marking range for 
a standard presentation. If this was the case it may have masked the impact of the formative assessment.

A third reason for this lack of improvement between the experimental groups could have been because the formative assessment was explained to the students as an experience to help them learn and was designed to have as little impact on the teaching staff workload as possible. This was achieved by not assigning any additional marks for the formative assessment, but instead imposing certain penalty marks for nonparticipation. The lack of marks, however, could also have been a disincentive for students to expend any significant effort in this task. To investigate this Table 5 illustrates the percentage of students that did not engage with the formative assessments. Across the three semesters, on average $20 \%$ of the students did not engage. Due to the conditions of unidentifiable data analysis to obtain ethics approval for this research, the authors are unable to determine if those that did not participate where in fact the students that needed the most improvement and did not take advantage of the opportunity.

TABLE 5: Student participation in providing feedback

\begin{tabular}{|c|c|}
\hline Semester / Year & Students Providing Poor or No Feedback \\
\hline Sem2 2014 & $19 \%$ \\
\hline Sem1 2015 & $10 \%$ \\
\hline Sem2 2015 & $32 \%$ \\
\hline
\end{tabular}

\subsection{Student Feedback}

During the implementation of experimental Group Two a survey was conducted to understand the student perception of the self and peer assessment tasks, together with the feedback received. The first question as shown in Figure 2, is used to determine if the students felt like they had benefited from watching their own performance on video. 
At least $65 \%$ of the students that responded to the survey believe that watching their performance did have some benefit. This finding is consistent with the work of many authors including McNulty and Lazarevic (2012), Hsia, Huang, and Hwang (2016), Rodriguez, Ajjan, and Honeycutt (2014) and Tazijan et al. (2012).

Interestingly, but not surprising, up to $24 \%$ of respondents stated that they did not reflect on their presentations. This is a similar percentage shown in Table 5 in regard to not engaging with the peer feedback. The authors suggest that apart from the disincentive due to lack of marks, this is related to students' time management skills. Whilst students have the option to record, watch, assess and repeat the cycle as many times as they wished, observing video presentations submitted just before the submission deadline showed an expected decline in quality. For many of the last minute submissions it appeared obvious that the presentation itself was conducted in the last minutes before the due date and time and no consideration was made to improve the performance, with the objective being simply to submit a video in order to avoid penalty marks being imposed. For some, this response could be due to confidence in their presentation ability.

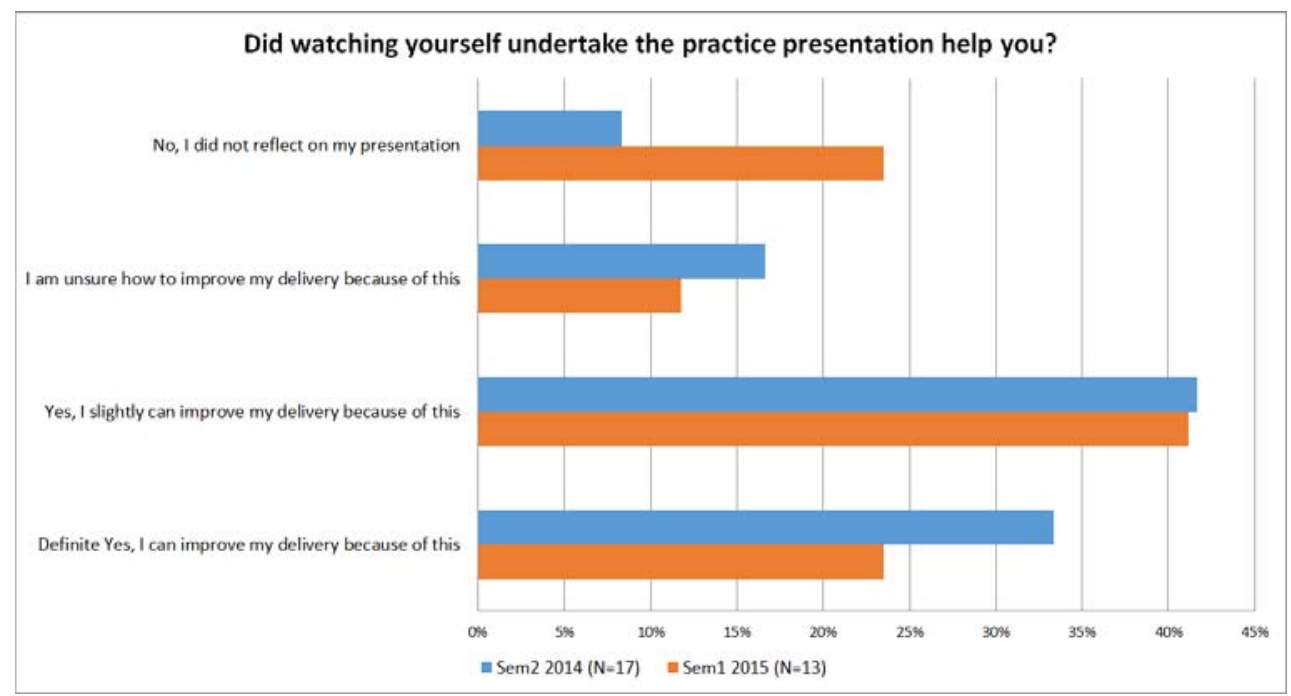

FIGURE 2: Student responses to the question 'Did watching yourself undertake the practice presentation help you?' 
The second survey question investigated the perception of the usefulness of the feedback for the students that responded to the survey. Figure 3 indicates that all students that reviewed the feedback thought that it was at least slightly useful. This finding is consistent with the work of Hsia, Huang, and Hwang (2016) who found that a combination of both ratings and peer comments can be very beneficial for learning. A number of students choose to ignore the feedback provided and the majority of these responses also came from the students that ignored the opportunity to reflect on their video performance. Again, the absence of any marks to force students to reflect on the feedback may have been a contributing factor.

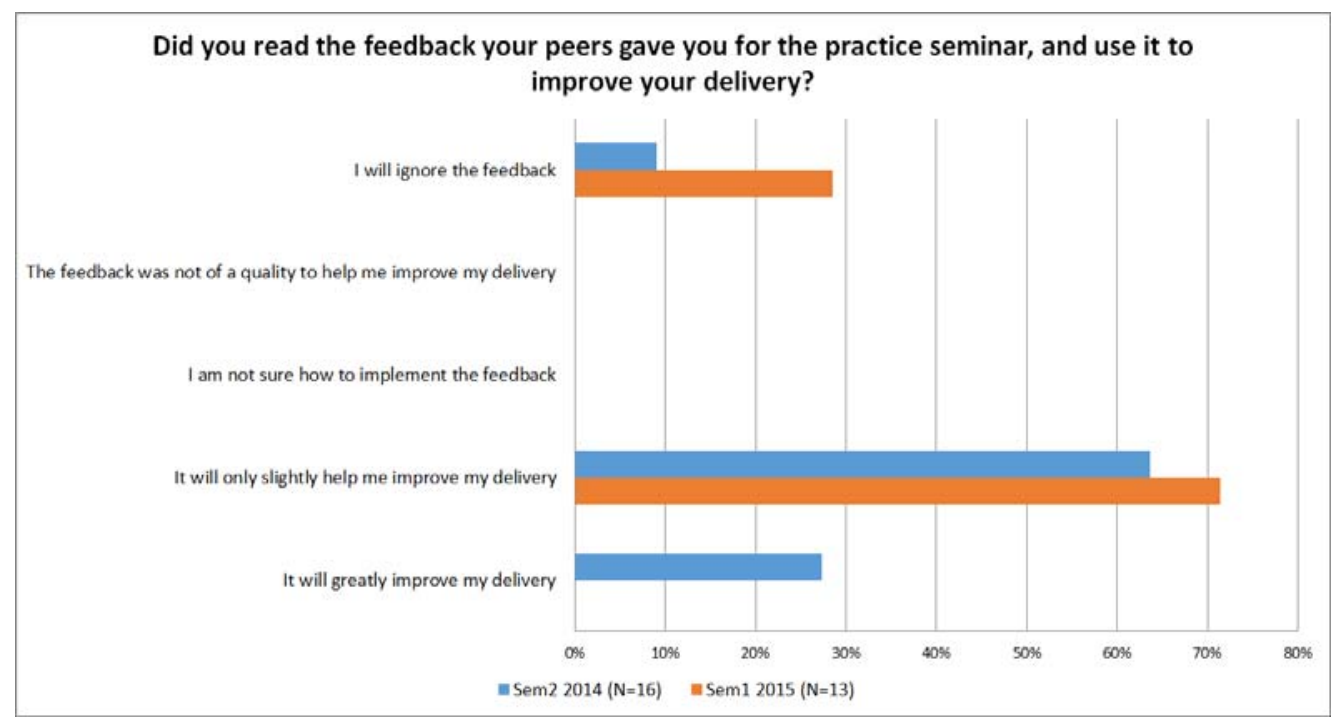

FIGURE 3: Student responses to the question 'Did you read the feedback your peers gave you for the practice seminar, and use it to improve your delivery?'

The third and final question, shown in Figure 4 is used to test the students' true perception of peer assessment by suggesting its use in another task. This would be the use of a literature review, another time-consuming task that students would benefit from extra feedback. At least $50 \%$ of students believed that this would be a good idea, approximately $15 \%$ were unsure and the rest were against the idea. This data suggests that at least half of the students do see the benefit of peer review. 


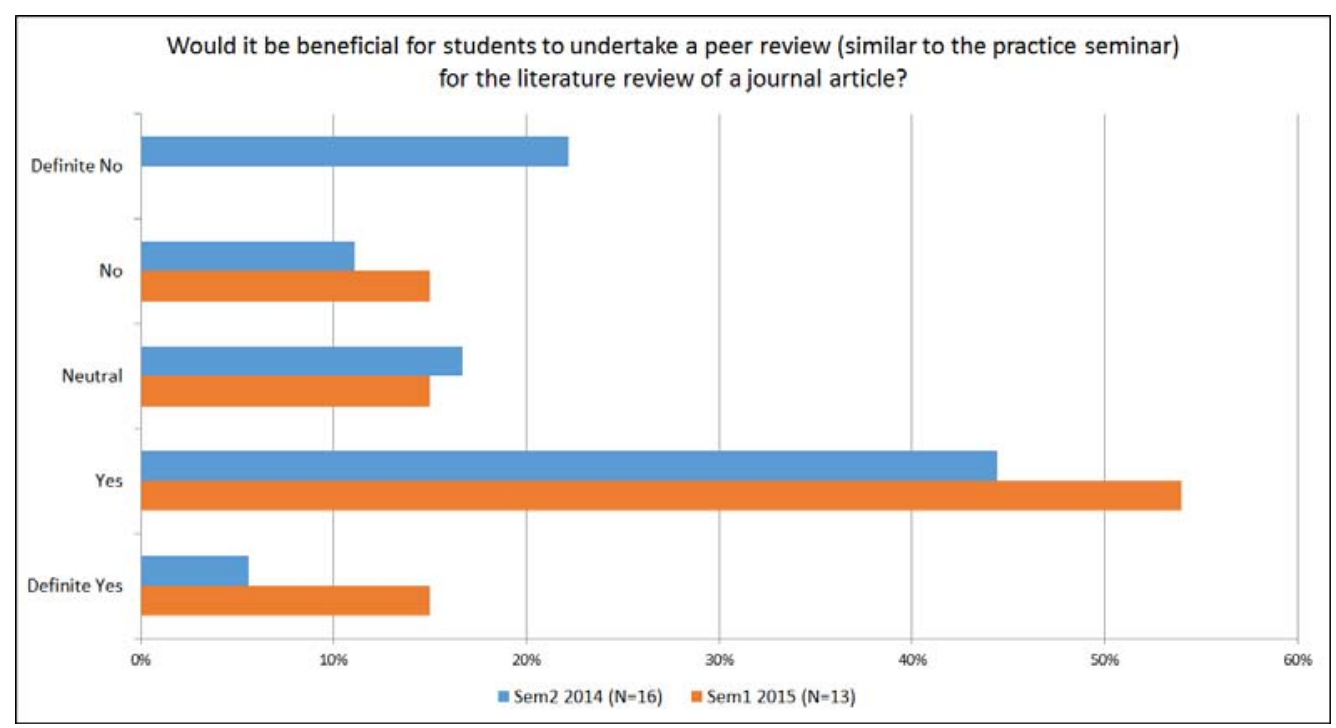

FIGURE 4: Student response to the question 'Would it be beneficial for students to undertake a peer review (similar to the practice seminar) for the literature review of a journal article?'

One of the requirements in this study was to limit additional workload on the teaching staff. The students were able to source video recording equipment on their own (most used their mobile phone) and upload their video onto YouTube without any direct help from the teaching staff. All that was required was the activation of a link on the learning management system for students to upload their YouTube links to, taking about two minutes. When all the links were provided the teaching staff were required to extract the information from the learning management system and into a spreadsheet, correct formatting errors with the links and divide the students into groups, a task that takes about 30 minutes. The longest stage requires uploading the students, groups, settings and marking criteria into Spark+. After the initial learning curve this was typically achieved within an hour. Therefore, the total workload required for teaching staff to implement this formative assessment approach is an hour and a half. 


\section{Conclusion}

This study investigated the implementation of two formative approaches to improve oral competency of fourth year engineering students while keeping workload on the teaching staff to a minimum. This involved recorded video, self-assessment, peer assessment and reflection. The formative assessments did not count towards the final grade, but were marketed as an opportunity for students to practice, reflect and improve their graded live oral presentation. Whilst the survey data showed that the majority of students found a benefit in the self and peer assessment process, this did not translate into significantly improved live oral presentation skills as measured by the experimental groups. The authors suggest three reasons, the first being that the students have already been exposed to numerous live presentations throughout their degree, and any further improvement would not be identified as significant. The second reason could be that the assessors were positioning most marks into a default region. The third being that as the formative tasks were not counted towards the final grades of the subject, students that could have improved the most did not engage with the activity. Another study, using a different course is currently underway to investigate if the impact of the formative assessments tasks can be improved by assigning grades that contribute to the final assessment mark.

This paper has contributed to engineering education research by showcasing a formative assessment method that the students considered beneficial for learning and that was relatively low workload for the teaching staff. While an improvement in grades was not identified, this work provides a framework for other researchers to build upon with a number of lessons learned. In particular, it would be of interest to try this approach on first year students. Whilst this study focused on the benefits of improving oral competency, the three assessment activities play an important role in developing students evaluation, critiquing and reflection skills. These are skills associated with 
higher order learning development as outlined in Blooms Taxonomy, and related to an engineering thesis. Faculty interested in helping students develop these higher order skills may find the approach used in this study beneficial for use in the classroom.

\section{References}

Abbott, Robert D., Donald H. Wulff, and C. Kati Szego. 1989. "Review of research on TA training." Review of. New Directions for Teaching and Learning 1989 (39):111-24. doi: 10.1002/tl.37219893912.

Anderson, Lorin W, David R Krathwohl, Peter W Airasian, Kathleen A Cruikshank, Richard E Mayer, Paul R Pintrich, James Raths, and Merlin C Wittrock. 2001. "A taxonomy for learning, teaching, and assessing: A revision of Bloom's taxonomy of educational objectives, abridged edition." Review of. White Plains, NY: Longman.

Australian Government. 2016. "Australian Qualifications Framework." Accessed 12 Feb. http://www.aqf.edu.au/.

Bandura, Albert. 1997. "Self-efficacy: The exercise of control." In.: New York: Freeman.

Barry, Shane. 2012. "A video recording and viewing protocol for student group presentations: Assisting self-assessment through a Wiki environment." Review of. Computers \& Education 59 (3):855-60. doi: http://dx.doi.org/10.1016/j.compedu.2012.04.008.

Beamish, B, M Kizil, K Willey, and A Gardner. 2009. Monitoring mining engineering undergraduate perceptions of contribution to group project work. Paper presented at the 20th Annual Conference for the Australasian Association for Engineering Education, 6-9 December 2009: Engineering the Curriculum.

Berjano, Enrique, Laura Sales-Nebot, and Albert Lozano-Nieto. 2013. "Improving professionalism in the engineering curriculum through a novel use of oral presentations." Review of. European Journal of Engineering Education 38 (2):121-30.

Bower, Matt, Michael Cavanagh, Robyn Moloney, and MingMing Dao. 2011. "Developing communication competence using an online Video Reflection system: pre-service teachers' experiences." Review of. Asia-Pacific Journal of Teacher Education 39 (4):311-26.

Brown*, Travor, and Lynn Morrissey. 2004. "The effectiveness of verbal self-guidance as a transfer of training intervention: its impact on presentation performance, self efficacy and anxiety." Review of. Innovations in Education and Teaching International 41 (3):255-71.

Calcich, Stephen E, and Dan C Weilbaker. 1992. "Selecting the optimum number of inclass sales presentations." Review of. Marketing Education Review 2 (1):31-3.

Chen, Chao-hsiu. 2010. "The implementation and evaluation of a mobile self-and peerassessment system." Review of. Computers \& Education 55 (1):229-36.

Cheng, Winnie, and Martin Warren. 2005. "Peer assessment of language proficiency." Review of. Language Testing 22 (1):93-121.

Cochrane, TA. 2009. "Enhancing oral presentation skills of engineering students: technology to the rescue with the virtual-i presenter (ViP)." In Proceedings of the 2010 ASEE. Washington, DC. 
Cochrane, Thomas A, and Michael O'Donoghue. 2008. "Improving oral presentation skills of engineering students with the Virtual-i Presenter (ViP) program." In 2008 Australasian Association for Engineering Education (AAEE) Conference.

Dannefer, Elaine F, Lindsey C Henson, S Beth Bierer, Tana A Grady-Weliky, Sean Meldrum, Anne C Nofziger, Craig Barclay, and Ronald M Epstein. 2005. "Peer assessment of professional competence." Review of. Medical education 39 (7):713-22.

De Grez, Luc, and Martin Valcke. 2013. "Student response system and how to make engineering students learn oral presentation skills." Review of. International Journal of Engineering Education 29 (4):940-7.

De Grez, Luc, Martin Valcke, and Irene Roozen. 2012. "How effective are self-and peer assessment of oral presentation skills compared with teachers' assessments?" Review of. Active Learning in Higher Education 13 (2):129-42.

Edwards, Daniel, Kate Perkins, Jacob Pearce, and Jennifer Hong. 2015. "Work Integrated Learning in STEM in Australian Universities." Review of. Canberra: Office of Chief Scientist \& Australian Council for Educational Research:1-120.

Elfering, Achim, Simone Grebner, and Silke Wehr. 2012. "Loss of Feedback Information Given during Oral Presentations." Review of. Psychology Learning \& Teaching 11 (1):66-76.

Engineers Australia. 2008. "G02 Accreditation Criteria Guidelines." In Education Programs at the level of Professional Engineer.

Freeman, Mark. 1995. "Peer assessment by groups of group work." Review of. Assessment \& Evaluation in Higher Education 20 (3):289-300.

Freeman, Mark, and Jo McKenzie. 2002. "SPARK, a confidential web-based template for self and peer assessment of student teamwork: benefits of evaluating across different subjects." Review of. British Journal of Educational Technology 33 (5):551-69.

Guo, Ruth Xiaoqing. 2013. "The use of video recordings as an effective tool to improve presentation skills." Review of. Polyglossia 24:92-101.

Hafner, John, and Patti Hafner. 2003. "Quantitative analysis of the rubric as an assessment tool: An empirical study of student peer-group rating." Review of. Int. J. Sci. Educ. 25 (12):1509-28.

Hsia, Lu-Ho, Iwen Huang, and Gwo-Jen Hwang. 2016. "Effects of different online peer-feedback approaches on students' performance skills, motivation and selfefficacy in a dance course." Review of. Computers \& Education 96:55-71. doi: http://dx.doi.org/10.1016/j.compedu.2016.02.004.

Kearney, Matthew, and Sandy Schuck. 2006. "Spotlight on authentic learning: Student developed digital video projects." Review of. Australasian Journal of Educational Technology 22 (2):189-208.

Kim, Ho Sung. 2014. "Uncertainty analysis for peer assessment: oral presentation skills for final year project." Review of. European Journal of Engineering Education 39 (1):68-83.

Koole, Sebastiaan, Tim Dornan, Leen Aper, Bram De Wever, Albert Scherpbier, Martin Valcke, Janke Cohen-Schotanus, and Anselme Derese. 2012. "Using video-cases to assess student reflection: Development and validation of an instrument." Review of. BMC medical education 12 (75):1-8.

Kunioshi, Nílson, Judy Noguchi, Hiroko Hayashi, and Kazuko Tojo. 2012. "An online support site for preparation of oral presentations in science and engineering." Review of. European Journal of Engineering Education 37 (6):600-8. 
Lee, Doo Young, and Mark R. Lehto. 2013. "User acceptance of YouTube for procedural learning: An extension of the Technology Acceptance Model." Review of. Computers \& Education 61 (0):193-208. doi: http://dx.doi.org/10.1016/j.compedu.2012.10.001.

Liow, Jong-Leng. 2008. "Peer assessment in thesis oral presentation." Review of. European Journal of Engineering Education 33 (5-6):525-37.

Male, Sally, and Robin King. 2014. "Best Practice Guidelines for Effective Industry Engagement in Australian Engineering Degrees." In.

Maloney, Stephen, Sophie Paynter, Michael Storr, and Prue Morgan. 2013. "Implementing student self-video of performance." Review of. The Clinical Teacher 10 (5):323-7. doi: 10.1111/tct.12027.

McNulty, Anastassia, and Bojan Lazarevic. 2012. "Best practices in using video technology to promote second language acquisition." Review of. Teaching English with technology 12 (3):49-61.

Morales, Juan C., and Ferdinand Rosa. 2008. Video Recording Feedback to Improve Oral Presentation Skills of Engineering Students: A Pilot Study. Paper presented at the LACCEI International Latin American and Caribbean Conference for Engineering and Technology, Tegucigalpa, Honduras.

Nabila, A. Bousaba, M. Conrad James, L. Coco Jean, Miri Mehdi, and W. Cox Robert. 2014. "Incorporating Oral Presentations into Electrical and Computer Engineering Design Courses: A Four-Course Study." In. Indianapolis, Indiana: ASEE Conferences.

Nicol, David, and Colin Milligan. 2006. "Rethinking technology-supported assessment practices in relation to the seven principles of good feedback practice." In Innovative assessment in higher education, edited by Cordelia Bryan and Karen Clegg, 64-77. New York USA.

Nikolic, Sasha. 2015. "Understanding How Students Use and Appreciate Online Resources in the Teaching Laboratory." Review of. International Journal of Online Engineering 11 (4):8-13. doi: http://dx.doi.org/10.3991/ijoe.v11i4.4562.

Nikolic, Sasha, Peter J. Vial, Montserrat Ros, David Stirling, and Christian Ritz. 2015. "Improving the Laboratory Learning Experience: A Process to Train \& Manage Teaching Assistants." Review of. IEEE Transactions on Education 58 (2):130-9. doi: http://dx.doi.org/10.1109/TE.2014.2335712.

Poza-Lujan, J. L., C. T. Calafate, J. L. Posadas-Yag, x00Fc, and J. C. Cano. 2016. "Assessing the Impact of Continuous Evaluation Strategies: Tradeoff Between Student Performance and Instructor Effort." Review of. IEEE Transactions on Education 59 (1):17-23. doi: 10.1109/TE.2015.2418740.

Prescott, David, Tharwat El-Sakran, Lutfi Albasha, Fadi Aloul, and Yousef Al-Assaf. 2012. "Teambuilding, innovation and the engineering communication interface." Review of. American Journal of Engineering Education (AJEE) 3 (1):29-40.

Price, Margaret, and Berry O'Donovan. 2006. "Improving performance through enhancing student understanding of criteria and feedback." In Innovative assessment in higher education, edited by Cordelia Bryan and Karen Clegg, 100-9. New York, USA: Routledge.

Rodriguez, Michael, Haya Ajjan, and Earl Honeycutt. 2014. "Using Technology to Engage and Improve Millennial Students' Presentation Performance." Review of. Atlantic Marketing Journal 3 (2):16-32.

Schmidt, Richard A, and Craig A Wrisberg. 2008. Motor learning and performance: A situation-based learning approach. Champaign, IL, USA: Human Kinetics. 
Taras, Maddalena. 2008. "Summative and formative assessment Perceptions and realities." Review of. Active Learning in Higher Education 9 (2):172-92.

Tazijan, Farina Nozakiah, Suzana Ab Rahim, Fauziah Saadah Abdul Halim, Aznizam Abdullah, IsmaNoornisa Ismail, and Thomas A Cochrane. 2012. "Implementing a Virtual Presentation Program in ESLClassrooms." Review of. International Journal of e-Education, e-Business, e-Management and e-Learning 2 (3):21822.

Topping, Keith. 1998. "Peer assessment between students in colleges and universities." Review of. Review of Educational Research 68 (3):249-76.

- 2003. "Self and peer assessment in school and university: Reliability, validity and utility." In Optimising new modes of assessment: In search of qualities and standards, 55-87. Dordrecht, Netherlands: Springer.

Trevelyan, James. 2014. The making of an expert engineer. London, UK: CRC Press/Balkema.

van Ginkel, Stan, Judith Gulikers, Harm Biemans, and Martin Mulder. 2015a. "The impact of the feedback source on developing oral presentation competence." Review of. Studies in Higher Education 0:0 (1-15).

_ 2015b. "Towards a set of design principles for developing oral presentation competence: A synthesis of research in higher education." Review of. Educational Research Review 14:62-80. doi: http://dx.doi.org/10.1016/j.edurev.2015.02.002.

Vial, Peter J., Sasha Nikolic, Montserrat Ros, David Stirling, and Parviz Doulai. 2015. "Using Online and Multimedia Resources to Enhance the Student Learning Experience in a Telecommunications Laboratory within an Australian University." Review of. Australasian Journal of Engineering Education 20 (1):71-80. doi: http://dx.doi.org/10.7158/D13-006.2015.20.1.

Willey, Keith, and Anne Gardner. 2008. "Using self and peer assessment for professional and team skill development: do well functioning teams experience all the benefits?" In ATN Assessment. Adelaide.

Živković, Slađana. 2014. "The importance of oral presentations for university students." Review of. Mediterranean Journal of Social Sciences 5 (19):468-75. 